This item was submitted to Loughborough's Research Repository by the author.

Items in Figshare are protected by copyright, with all rights reserved, unless otherwise indicated.

\title{
Responses of track and field coaches to athletes with eating problems
}

\section{PLEASE CITE THE PUBLISHED VERSION}

http://dx.doi.org/10.1111/sms.12286

PUBLISHER

() John Wiley and Sons

\section{VERSION}

AM (Accepted Manuscript)

\section{LICENCE}

CC BY-NC-ND 4.0

\section{REPOSITORY RECORD}

Plateau, Carolyn R., Jon Arcelus, Hilary McDermott, and Caroline Meyer. 2014. "Responses of Track and Field Coaches to Athletes with Eating Problems". Loughborough University. https://hdl.handle.net/2134/15239. 
This item was submitted to Loughborough's Institutional Repository (https://dspace.lboro.ac.uk/) by the author and is made available under the following Creative Commons Licence conditions.

\section{creative
commons}

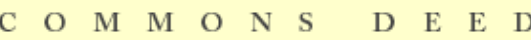

Attribution-NonCommercial-NoDerivs 2.5

You are free:

- to copy, distribute, display, and perform the work

Under the following conditions:

Attribution. You must attribute the work in the manner specified b the author or licensor.

Noncommercial. You may not use this work for commercial purposes.

No Derivative Works. You may not alter, transform, or build upon this work.

- For any reuse or distribution, you must make clear to others the license terms of this work.

- Any of these conditions can be waived if you get permission from the copyright holder.

Your fair use and other rights are in no way affected by the above.

This is a human-readable summary of the Leqal Code (the full license).

\section{Disclaimer 만}

For the full text of this licence, please go to: http://creativecommons.org/licenses/by-nc-nd/2.5/ 
Responses of Track and Field Coaches to Athletes with Eating Problems

Date submitted: $19^{\text {th }}$ May 2014

Carolyn R Plateau, MRes* ${ }^{\mathrm{a}}$

Jon Arcelus, FRCPsych, PhD ${ }^{\mathrm{a}, \mathrm{b}}$

Hilary J McDermott, $\mathrm{PhD}{ }^{\mathrm{a}}$

Caroline Meyer, PhD. ${ }^{\text {a, b }}$

${ }^{a}$ Loughborough University Centre for Research into Eating Disorders

Loughborough University

Loughborough, LE11 3TU, UK.

${ }^{\mathrm{b}}$ Leicester Adult Eating Disorders Service

Bennion Centre, Glenfield Hospital, Groby Road,

Leicester, LE3 9DZ, UK.

*Corresponding author: Carolyn Plateau, Loughborough University Centre for Research into

Eating Disorders, Loughborough University, Loughborough, LE11 3TU. Phone: (+44) 1509 228151 Email: C.R.Plateau@lboro.ac.uk 


\begin{abstract}
This study aimed to explore how track and field coaches respond to athletes with eating problems. Eleven experienced coaches participated in semi-structured interviews exploring their responses to, and challenges faced when, working with athletes with eating problems. The analysis revealed three themes relating to the strategies employed by coaches. The first theme indicated a supportive approach, where coaches were proactive in seeking support and in reducing training at the early stages of an eating problem. The second theme outlined an avoidant approach, characterised by coach reluctance to be involved in managing eating problems, and a lack of confidence in their knowledge of eating disorders. The third theme involved a confrontational approach, where coaches employed strict rules and engaged in coercion to persuade athletes to seek treatment. All of the coaches reported facing challenges in persuading athletes to seek treatment and were frustrated by a lack of available support. The study highlights the importance of providing resources and support services where coaches can seek advice. Coach education packages can utilise the findings to highlight the strengths and limitations of different coach strategies, and to reinforce the importance of their role in identification and intervention when eating problems in athletes are suspected.
\end{abstract}

Key words: eating disorders, coaching, education, prevention, sport 
Responses of Track and Field Coaches to Athletes with Eating Problems

Athletes have been identified as a group who are particularly vulnerable to the development of eating disorders, with nearly $20 \%$ of elite female and $8 \%$ of male athletes meeting clinical criteria (Sundgot-Borgen \& Torstveit, 2004). Studies exploring the prevalence rates of eating disorders among track and field athletes are somewhat limited, as a result of small sample sizes, differing diagnostic criteria, varying competitive levels and mixed sport samples (Hausenblas \& McNally, 2004; Johnson, Powers \& Dick, 1999). The evidence has, however, suggested that athletes competing in sports such as track and field, where a lean physique is deemed advantageous, are at an elevated risk of eating problems (e.g., Torstveit, Rosenvinge \& Sundgot-Borgen, 2008). Specifically, this includes endurance, anti-gravitation, and high intensity events - such as middle distance running - where competitors have been found to be at an increased risk of eating problems (e.g., SundgotBorgen \& Torstveit, 2010). Furthermore, indicators of insufficient energy intake, such as menstrual disturbances among female athletes (Bennell et al., 1996a), and reduced bone mineral density and/or bone stress injuries, occur at a high incidence within track and field athletes (Duckham et al., 2012; Nattiv, 2000; Pollock et al., 2010).

The suggested high prevalence of eating disorders among athletes has prompted a considerable amount of research into the potential risk factors (e.g., Petrie, Greenleaf, Reel \& Carter, 2009; Torstveit et al., 2008). In addition to the more general risk factors for eating disorders (e.g. self-critical perfectionism, low self-esteem and depressive symptoms), coach attitudes and behaviours towards athlete weight have been identified as potential triggers of disordered eating (e.g., Jones, Glintmeyer \& McKenzie, 2005; Turk, Prentice, Chappell \& Shields, 1999). For example, encouraging athletes to engage in weight-loss strategies, without providing adequate support and guidance for doing so (Sundgot-Borgen, 1994); criticising an athlete’s weight and shape (Goodwin, Arcelus, Marshall, Wicks \& Meyer, 
2013; Muscat \& Long, 2008); engaging in regular weight and nutritional monitoring practices (McMahon \& Dinan-Thompson, 2008) and placing a high priority on weight for performance (Jones et al., 2005) are practices that can increase athlete body surveillance and awareness, with the potential for triggering and/or perpetuating the development of disordered eating among vulnerable individuals (e.g., Jones et al., 2005; McMahon, Penney \& Dinan-Thompson, 2012). Similarly, athletes who describe a poor quality relationship with their coach, characterized by high levels of conflict and low levels of support, report higher levels of eating psychopathology than those who describe a good relationship (Shanmugam, Jowett \& Meyer, 2013).

In contrast to the reported opinion that coaches can elicit eating problems in athletes, coaches have been identified as having an important role in recognizing the signs and symptoms of eating disorders within their athletes (Selby \& Reel, 2011). Coaches are acknowledged as an important source of support when working with athletes suffering from disordered eating and also have a role in encouraging treatment seeking (Sundgot-Borgen \& Torstveit, 2010). Research has suggested reluctance among athletes in seeking support for mental health problems (Gulliver, Griffiths \& Christensen, 2012); the reasons for which are largely similar to those reported among the general population (e.g. Hunt \& Eisenberg 2010). Athletes cite concerns over the stigma associated with mental illness, a lack of mental health literacy and negative previous experiences of help-seeking as barriers to support seeking for mental health issues (Gulliver et al., 2012). It is important to note, however, that encouragement from the coach has been identified as a key motivator for athletes to access support services (Gulliver et al., 2012). Specifically, athletes who have recovered from an eating problem have cited intervention by their coach and imposed reductions of training as useful and necessary strategies in promoting help-seeking behaviours (Arthur-Cameselle \& Baltzell, 2012). 
There is evidence to suggest that coaches lack the knowledge to identify the signs and symptoms of eating problems, and also experience difficulties in approaching athletes when they suspect a potential eating problem (Sherman, Thompson, DeHass \& Wilfert, 2005; Turk et al., 1999). In particular, coaches express concerns about potentially exacerbating an existing problem or triggering an eating problem among vulnerable athletes (Plateau, McDermott, Arcelus \& Meyer, 2013). A recent study conducted with elite coaches in Sweden revealed the difficulties they experienced in accessing sufficient resources and support when working with an athlete with an eating problem, particularly regarding signposting athletes to appropriate support services for treatment (Nowicka, Eli, Ng, Apitzsch \& Sundgot-Borgen, 2013). It is apparent that coaches face similar challenges in supporting athletes with eating problems as athletes themselves face in acknowledging and seeking support for eating problems. The evidence suggests that logistical and internal challenges exist for both coaches and their athletes when faced with the prospect of an eating disorder.

Such challenges remain despite recent increases in the information available for coaches about identification and management of eating problems both within the scientific literature (Selby \& Reel, 2011, Thompson \& Sherman, 2010) and in specific coaching resources from sport federations (National Collegiate Athletic Association, 2005; UK Sport, 2007). It has been suggested that the translation of eating disorder knowledge into action may be particularly problematic for coaches (Nowicka et al., 2013). Only a small body of research has explored in-depth the challenges that coaches face when working with an affected athlete and their relative involvement in the treatment-seeking process, directly from the perspective of coaches themselves (Sherman et al., 2005; Nowicka et al., 2013). This research has also primarily been done with coaches at the elite level. Support protocols developed by sports federations are often specific to elite athletes; with limited procedures for athletes competing below this level (UK Athletics, 2013). Understanding the challenges that face sub-elite 
coaches may have much wider implications for coach education, particularly with regards to supporting coach intervention and treatment seeking among athletes with eating problems.

The literature has highlighted the importance of the coach in facilitating and supporting treatment seeking among athletes with eating problems, and the field has begun to consider how sports coaches in general handle such a situation. It is probable, however, that individual differences exist both between coaches and across different sporting contexts. Likewise, individual differences have been demonstrated among caregivers of eating disordered individuals (Treasure, Smith \& Crane, 2007) and these differences are believed to have a significant impact on the course and outcome of an eating disorder (Schmidt \& Treasure, 2010). There is a clear need to explore in depth the emotional reactions, underlying beliefs and management strategies of track and field coaches when faced with an athlete with an eating problem. The following research aims were explored: (a) What strategies do track and field coaches use when responding to an athlete with an eating problem? How do strategies vary between coaches? (b) What are the challenges that coaches face when working with an athlete with an eating problem? The study is reported according to the consolidated criteria for reporting qualitative research checklist (COREQ;Tong, Sainsbury \& Craig, 2007).

\section{Method}

\section{Participants}

Eleven UK track and field coaches were recruited to take part in the study. The coaches were aged between 44 and 69 years and ten (91\%) were male. All of the coaches reported encountering disordered eating or clinical eating disorders among female athletes during their time coaching; six of the coaches reported currently coaching an athlete with an eating problem. One coach reported having encountered eating problems among male athletes. The participants coached athletes of mixed abilities, including recreational and club 
level athletes, although all of the coaches reported currently coaching athletes at either national ( $n=5)$ or international level $(n=6)$. Two coaches reported currently coaching athletes who were receiving funding support from the national governing body. With regards to their current coaching context, all of the coaches reported that they were coaching voluntarily, with the majority coaching within a local club environment $(n=8)$; the remainder were coaching within a university environment. The characteristics of the coaches, including demographic information and coaching experience are shown in Table 1.

\section{Procedure}

Approval to conduct this study was provided by the Ethical Advisory Committee at the host institution prior to data collection (Reference number: R11-P69). Advertisements and information about the purpose of the study were emailed and/or posted to UK athletics clubs to recruit interested participants who met the inclusion criteria. Participants were also recruited from coach-education workshops. The inclusion criteria specified that coaches needed to have coached an athlete with an eating problem, to ensure that they could reflect on their personal experiences and to discuss any challenges they faced. Participants also had to be currently coaching for a minimum of one hour each week. Thirteen participants contacted the researcher for further information about the study, eleven of whom took part. The two coaches who dropped out did not provide a reason for doing so.

Following informed consent, the coaches took part in a single interview with a researcher, either in person $(n=1)$ or by telephone $(n=10)$, depending on their individual preference. Previous research has suggested that the frequency and depth of responses to interview questions are equivalent, whether interviews are conducted on the telephone or face-to-face (Sturges \& Hanrahan, 2004). It can be more difficult to develop a rapport with the participant on the telephone (Aquilino, 1994). One advantage of telephone interviewing, however, is the greater anonymity it provides in comparison to face-to-face interviews; which 
may be of particular importance when discussing sensitive topics, such as this. The interviews lasted between 43 and 69 minutes (mean 53.82 minutes) and were recorded and transcribed verbatim with the knowledge and consent of the participants. Participants were not asked to review the transcripts for their interview. Each interview involved only the participant and the researcher.

Semi structured interviewing was utilised as it can facilitate in-depth responses and provides the researcher with the flexibility to include additional questions and direct the interview as appropriate for each participant (Patton, 2002). The interview schedule was developed by a team of experts comprising psychologists, eating disorder specialists, a psychiatrist and sport scientists. In addition to providing information about their own experiences of managing an athlete with an eating problem, coaches were asked to respond to a two-part scenario outlining a female athlete with eating disorder symptoms. This approach has been identified as a way of determining people's actions in certain contexts, and is considered a less personal and less threatening way of exploring sensitive topics (Hughes, 1998). It allows participants to reflect upon and include personal experiences, as well as opening up the discussion and broadening the focus of the interview to more abstract experiences (Barter \& Renold, 2000). All of the interviews were conducted by the same researcher (the first author), who is an athlete currently competing at international level in track and field. The interviewer reiterated the purpose of the study at the start of the interview, and gave the participants the opportunity to ask further questions about the study. The participants were made aware of the interviewer's background in athletics, which facilitated the development of good rapport between the interviewer and the participant, through shared knowledge of the training and competition environments. The interview schedule is provided in Table 2.

\section{Data analysis}


A critical realist position was adopted for this study (Bhaskar, 1989). Critical realism offers an epistemological position that retains some of the strengths of both the realist and constructionist perspectives (Pilgrim \& Rogers, 2002). Critical realism suggests that our experiences and representations of reality are characterised and mediated by language, culture and social contexts. It therefore rejects both the stringent positivist position as well as the idealist position concerning reality construction (Pilgrim \& Rogers, 2002). In addition, critical realism suggests that lay knowledge and experiences are of equal status with the knowledge of professionals and specialists, and cautions against relying on knowledge only obtained from experts (Bhaskar, 1989). A critical realist approach encourages the involvement of lay participants in generating knowledge and improving expert understanding (Pilgrim \& Rogers, 2002).

Critical realism acknowledges that it is possible to acquire an insight into participant experiences through their verbal accounts of events (Bhaskar, 1989). This study therefore explored coach experiences of working with athletes with eating problems, through their own accounts and descriptions. A critical realist approach allowed the potential impact of sociocultural and contextual influences on participant experiences to be identified and acknowledged (Bhaskar, 1989). In this particular study, this involved consideration of the sociocultural norms and expectations engendered within the sporting context and the potential impact of this environment on coach experiences and their accounts of the events.

The transcribed interviews were imported into NVivo 9 (QSR, 2010), a qualitative data management tool that facilitates organisation and analysis of the data. An inductive thematic analysis was conducted, hence there was no pre-determined coding framework and the themes were entirely data driven (Patton, 1990). The analysis was conducted according to the six phases of thematic analysis outlined by Braun and Clarke (2006). The first phase involved familiarisation and immersion in the data through manual transcription of the 
interviews and reading and re-reading through the whole dataset. This process can facilitate the comprehension of the complexity of the data set (Smith \& Caddick, 2012; Whitaker, Backhouse \& Long, 2014). Initial thoughts about the data were recorded during this phase, prior to the more formal and systematic stages of coding. These preliminary notes, in conjunction with field notes made during the interview itself, were used to guide the early stages of the analysis. The second phase consisted of systematically labelling meaningful units of the text within NVivo 9 (QSR, 2010). A list of codes that occurred across the dataset was generated, and related codes were collated together. The third phase involved sorting the codes into relevant and meaningful themes and subthemes. These themes were then reviewed and re-organised to ensure that the data within each theme were appropriately related to that theme. Similarly, the themes were assessed to ensure there was sufficient distinction between them. Subsequently, the themes were assigned labels that accurately reflected the data. No new themes emerged in the analysis of the final two interviews, hence the number of participants was deemed sufficient. This method has been suggested as an appropriate way to identify when thematic saturation has been achieved (Guest, Bunce \& Johnson, 2006; Lentillon-Kaestner, Hagger \& Hardcastle, 2012). Finally, appropriate quotes were selected from each transcript that accurately reflected each theme. The analysis was reflexive in nature, whereby frequent discussions were held within the research team to discuss the generated themes, and to consider other possible ways of grouping and labelling the data. A reflexive approach has been identified as one method of enhancing the validity of qualitative research (e.g., Kristiansen, Tomten, Hanstad \& Roberts, 2012; Partington \& Cushion, 2013). Similarly, a sample of the data was independently coded by a second researcher, who had extensive qualitative experience. Discussions were held between the two researchers, revealing no major disagreements in the codes applied to the data sample, further supporting the validity of the findings. The themes were minimally adjusted during discussions to reach consensus. 


\section{Results}

Four main themes were identified. Three themes emerged with regards to responses and strategies reported by coaches when working with athletes with eating problems, while the fourth theme was that of the challenges that they faced in doing so. The initial three themes, labelled according to the types of strategies employed by coaches were: Supportive, Avoidant and Confrontational. The challenges that coaches faced in dealing with athletes with eating psychopathology included (a) availability and appropriateness of support, and (b) persuading athletes to seek treatment.

\section{(1) Supportive}

A supportive approach was an important theme to emerge from the data, where coaches described a proactive strategy of seeking appropriate support for the athlete. A supportive approach was also characterised by a working partnership between the coach and the athlete, whereby coaches felt able to motivate athletes to seek treatment, to moderate training appropriately and to signpost athletes to additional sources of support.

Resourcefulness. An important component of the supportive theme was a resourceful approach to seeking support. Some of the coaches described seeking out the most appropriate form of support available to them, and a willingness to take a leading role in doing so. For example, a 56 year old university endurance coach stated: "I was really looking for a clinical psychologist. And not only did I want a clinical psychologist, I wanted a clinical psychologist that dealt very, very proactively with eating disorders and disordered eating.” This particular coach goes on to explain how he took the lead in finding and approaching a psychologist when involved in coaching an athlete with an eating problem. 
I’m fortunate that I've been able to phone up people and say right, I need a contact, this is such and such. So I've been able to phone up a sport psychologist I trust a lot and say, I need somebody that knows about eating disorders.

Working in partnership. An important component of the supportive theme was the development and implementation of clear objectives among coaches to support the athlete towards help seeking, with a primary aim of working with the athlete in tackling the eating problem. Coaches aimed to facilitate this partnership with the athlete primarily through establishing and maintaining good communication channels. Regular, open communication with the athlete ensured that the coach was kept up to date with the athlete's progress, and allowed the coaches to provide emotional support where necessary. Establishing and committing to common goals with an athlete was identified as an important feature of a successful collaboration and coach-athlete relationship. For example, this 52 year old university endurance coach stated:

The way to make it successful is if the athlete and coach feel as if they're a team, working together towards a goal, whatever that goal may be...if you're there with them, working together to try and help them to put on weight... It doesn’t work if it becomes somebody saying you must do this or that.

Moderating training. A third component of a supportive strategy was to intervene and reduce training in the early stages of an eating problem, reflecting a desire of coaches to protect the health of the athlete. Indeed, such a strategy was often described as an attempt to motivate athletes to recover through a manipulation of prescribed training amounts. For instance, the quantity of training prescribed was often closely linked to an athlete's weight, with increases in training permitted with weight gain or weight maintenance, but equally 
reductions in training enforced where the athletes did not meet agreed weight targets. This process was described by a 63 year old coach club-based endurance coach.

She was doing three short runs a week at home and they were really short, just until we'd made sure she was maintaining her weight and increasing it before we increased anything. And that was a sort of a carrot to have...but if she didn’t eat enough to give her the energy to do the training then she wouldn't be coming training the next week. But, it seemed to work.

Signposting. A final element identified in the supportive strategies employed by coaches was a proactive approach in seeking support for their athlete. This included a high level of awareness of when to signpost athletes with eating problems to other sources of support as the severity of the problem heightened. Coaches endorsing a supportive strategy often described taking an active role in the early stages, by seeking out potential sources of support, such as searching for information and support online, seeking advice from other coaches or from the welfare officer within their club. In addition, a small number of coaches showed an awareness of when to signpost athletes to more specialist support services. One 52 year old university endurance coach accepted, "When it reaches a certain level, you have to accept as a coach that you're not going to be able to sort everybody out, and there might be the odd person who needs professional help.”

\section{(2) Avoidant}

The second theme to emerge was avoidance, where coaches noticeably lacked a clear strategic approach to dealing with eating problems among athletes. In particular, some coaches demonstrated an unwillingness to deal proactively with a potential eating problem. This manifested as assigning alternative explanations for weight loss, expressing a lack of confidence in their knowledge about eating problems, and perceiving the management of a 
potential eating problem to fall outside of their role as a coach. Avoidant responses by coaches were most apparent when an eating problem had yet to be formally diagnosed or identified. In some cases, coaches who initially employed avoidant strategies were able to provide a more supportive response once parents or medical professionals were also involved.

Denial. A key component of an avoidant strategy was a tendency of some coaches to deny the presence of an eating problem among their athletes. Instead, the coaches preferred to consider alternative explanations for alterations to their athletes eating behaviours and appearance. For instance, observed weight loss among athletes was frequently attributed to alternative factors such as to lifestyle, training habits or other explanations that were perhaps less distressing or concerning for the coaches. In response to the first part of the scenario, a 57 year old university endurance coach stated: "It may well be that someone is losing weight not necessarily because they've got an eating disorder, but actually just because they're not getting organised, it could just be poor time management.” This could be problematic in delaying access to treatment, and could potentially allow time for the severity of eating psychopathology to escalate.

Responsibility. Avoidant responses by coaches were also characterised by an unwillingness to take responsibility for athletes with eating problems, both in terms of facilitating support seeking and in reducing training appropriately. Instead, these coaches tended to leave this responsibility to parents, medical support or even the athletes themselves. Although coaches should not be expected to take primary responsibility for dealing with an athlete with an eating problem, and should be encouraged to involve other sources of support, coaches employing more avoidant strategies tended to be quite passive in addressing a potential eating problem. Indeed, in some cases, any involvement in managing athletes with eating problems was perceived to be outside of the 'remit' of the role of the voluntary coach 
and beyond their level of expertise. For example, one 44 year old club-based endurance coach stated:

I'm just an amateur, dabbling, not necessarily in the coaching, but in terms of all these sort of fringe issues, for want of a better description. What I may know, it might be right, it might not be, I don't know. Sometimes you get to the point where you think I've got a full time job, I do this in my spare time; I really don't need this amount of hassle.

An avoidance of responsibility among coaches was also associated with a poor knowledge of eating problems in this group. In addition, these coaches perceived their relative influence over their athletes as very low, particularly in terms of persuading them to seek treatment or to change their eating behaviours, and this was reflected in their reliance on the involvement of others. Indeed, one 58 year old club-based endurance coach suggested that their role in dealing with athletes with eating disorders was minimal:

Well I think my only contribution as a coach is trying to keep things normal for them. But it's about liaising with parents and seeing, making sure that you can do what they want, what they need to get their child back on course.

In addition, coaches who were unwilling to take a role of responsibility in dealing with athletes with eating problems also described a lack of accessible resources and knowledge of where athletes could seek support. It is plausible that the passive approach characterising avoidant strategies was exacerbated by a perceived lack of available support for athletes and coaches alike. As a consequence, however, it was noted that as the severity of eating psychopathology escalated, some of the coaches were prone to withdrawal, preferring for another coach to intervene. Indeed, some coaches expressed a reluctance to continue coaching the athlete. One 57 year old university endurance coach described: "When you get to that [severe] stage, I think people need serious psychiatric support. I mean it sounds really harsh but it's gone beyond anything that a coach or GP can deal with.” 
Concern and anxiety over exacerbating the situation. Finally, coaches employing avoidant strategies also described considerable anxiety and concern about doing or saying something that could elicit or exacerbate the severity of the eating problem. This often resulted in a tendency to take no action, or to significantly delay action with regards to the eating problem. Coaches described this strategy as preferable in comparison to tackling the situation directly and potentially risking an unfavourable outcome. For example, one 69 year old club-based endurance coach describes his concerns about approaching athletes when they suspected an eating issue. "If I was stupid enough to say now some of you look a bit underweight to me, I don’t know if you’ve been... you know that would be absolutely disastrous if they were doing something.”

\section{(3) Confrontational}

The third emergent theme comprised confrontational responses, typified by coachathlete battles over the need to seek treatment and in the reduction of training. Coaches employing confrontational approaches often used scare tactics, imposed strict rules and targets for weight or training, and tried to coerce the athletes into seeking treatment.

Rules and conditions. Coaches who tended to use confrontational strategies often described imposing a series of rules or regulations with their athletes, in an attempt to secure some degree of control over the athlete's eating behaviours. Such rules were often put in place to help the coach determine when to stop an athlete from training, and the coaches seemed to be more comfortable when they knew they had such procedures in place. For example, a 56 year old male, endurance coach stated with regards to the body fat percentages that he imposed for his female athletes:

If then I'm seeing things that I don't like, such as less than fifteen percent, then we have a you know, a fairly strong conversation about this has to be addressed. This is a 
safe weight for you and that's where I want you to be. And I promise you, you will stay at that weight and long term you will run much better than where you are now.

In this particular case, the coach encouraged the athlete to adhere to the set target by using performance improvement as an incentive. It is clear that this coach held strict views on appropriate body fat percentages for athletes. Such an approach may be interpreted negatively by athletes, particularly where they fall above the perceived "ideal weight”. This quote also suggests a tendency towards an authoritarian coaching style, where the coach maintains considerable power and control over the athlete, with few opportunities for the athlete to be autonomous. The target weights and body fat percentages that coaches often used to determine the athlete's health and ability to continue training, were not advised by medical professionals, but rather developed through their own experience and interpretation, as described by a 52 year old male endurance coach.

If they get under 50 [millimetres] then I see that as quite a red flag. That's my observation, you know, the people who do the skinfolds don't seem to come up with any, they have a very woolly statement about its all individual and you know you've got to find out what suits you.

One 56 year old male endurance coach described only agreeing to continue to coach an athlete if they adhered to the set rules and conditions that he had laid out, indicating a need for high levels of control over the athlete. The conditions were deemed as non-negotiable, with the penalty for not adhering to the conditions made clear to both the athlete and the parent.

What I've said to the parents, is if I do [continue coaching the athlete], it will be conditional on her giving me a public weigh-in. Not a weight that she gives me, but a 
weight that she, is seen to take supervised by her mum and dad. That would be conditional on me coaching her.

The insistence that the athlete must be supervised at a regular weigh-in indicates that the coach feels unable to trust the athlete to provide a truthful weight reading. This quote provides additional evidence of an authoritarian coaching style that existed among coaches employing confrontational strategies, with the balance of power shifted almost entirely in the direction of the coach. There are clear expectations for compliance, not only from the athlete themselves but also from their parents.

Battles and conflict. Coaches who demonstrated high levels of confrontation in their approach to dealing with athletes with eating problems, described particular difficulties in motivating the athlete to make changes to their training schedule, or in seeking appropriate support. In particular, unwillingness on the part of the athlete to comply with suggestions from the coach was identified as a major source of conflict. Coaches who reported difficulties in resolving conflicts with their athletes, also described concerns about their own knowledge of eating disorders, particularly with regards to when it is appropriate to stop an athlete from training. These coaches also expressed a lack of confidence in broaching the subject of training cessation with their athletes. Confrontational approaches to the reduction of training were often deemed as unsuccessful. For example, a 62 year old club endurance coach described being pressured by an athlete when he suggested a reduction in their training.

One of them did say, “Well, if you won’t train me, I’ll go and do it myself.” So basically you're in that sort of catch twenty-two situation, they really need to get a grip of this and stop training, but at the same time, you need them to be under control. If they're out on their own, you have no idea what's going on and how much work they're doing, which can be worse. 
In contrast to the Supportive theme, coaches exhibiting high levels of confrontation did not, or did not feel able, to reduce training at an early stage. In some cases, this resulted in an escalation in the severity of the eating problem, prompting parent and occasionally medical intervention. A collective intervention by the coach, parents and medical staff was often conducted to prevent the athlete from training. Importantly, where coaches felt unable to work with the athlete and where the athlete was unwilling to comply with their demands with regards to training cessation and treatment seeking, the outcome was often a termination of the coaching relationship. Such an outcome was often perceived as the only option in helping the athlete to recover. One such decision was described by a 69 year old club based endurance coach.

I had to make a judgement. I'd hate myself if I didn’t say anything and things went wrong, I have to take this chance. She didn’t want to stop, but I did say look, this doesn't mean I'm not still concerned about you and I will come and see you. And we did, for some time after, not meet up, but you know, if there was a local race down somewhere she would come along to watch and I would make sure I was there to have a word with her and ask about her studies and that sort of thing.

Scare tactics. A final characteristic of a more confrontational approach to managing athletes with eating problems was the use of scare tactics and manipulation, in an attempt to coerce athletes into seeking treatment for their eating problem. These manipulation tactics utilised by coaches tended to focus on the potential long term implications of an eating problem, both in terms of the athlete's health, and also their performance. One 56 year old male endurance coach described using health related scare tactics to convince athletes to seek support. 
You can just keep banging away and say you know, please seek some advice, please go and see a psychologist, please go and see your GP. If you don't address it you're going to make yourself very ill. And ultimately, you're threatening your life if you persist with it.

More commonly, coaches reported using performance related scare tactics to persuade athletes to seek support for their eating problems. Such an approach was perceived to be effective in instigating change among the athletes. One 52 year old, male endurance coach described how he used examples of athletes who had suffered from eating problems and how their performance had subsequently suffered as a result, in an attempt to coerce athletes into seeking help and support for their eating problem.

I would highlight the dangers of running when you're underweight, in terms of long term health, risk of stress fractures, and long term running health... if you want to have a long career in running, you know, you're playing with fire. There are so many examples in the sport of people who were successful at 17,18, 19, who because they didn’t look after themselves properly, have finished by the time they're 20 .

\section{(4) Challenges faced by coaches}

The final pervasive theme that occurred throughout the data was the challenges that coaches faced when working with athletes with eating psychopathology. These included (a) availability and accessibility of appropriate support and (b) persuading athletes to seek help for an eating problem.

Availability and accessibility of support. Nearly all of the coaches in the study expressed concerns about the treatment options available for athletes with eating problems, with many suggesting that the usual primary care route was not always appropriate. In particular, coaches expressed frustration at the lack of understanding of the specific needs of 
athletes by general practitioners, as well as the amount of time it often took to be referred to a specialist within the National Health Service. One 54 year old club-based endurance coach suggested that athletes should be treated more quickly than non-athletes.

I'd have liked to have understood rather better the process of referral, of getting people into the system and having some kind of back up for sports people - some kind of fast-tracking would have been extremely useful.

The coaches perceived their athletes to require specialist support and treatment, which may be a reflection of the level of the coaches and their athletes within this study; all of the participants were coaching at national or international level. Despite the concerns that primary care resources lacked specificity when dealing with athletes, most of the coaches felt that general practitioners (GPs) had significantly greater knowledge than themselves with regards to eating psychopathology, and were willing to follow their advice.

In response to their dissatisfaction with the primary care route, six of the 11 coaches described seeking additional support for their athletes outside of the UK National Health Service. Mostly, this involved sourcing support from a nutritionist or dietician to evaluate the athlete's nutritional status. However, this wasn’t always deemed a success, as described by a 52 year old university endurance coach: "I have sent people to a nutritionist, but a little bit down the road with some of these athletes, and they’ve said well I don’t know that I really got that much out of it.”

Coaches placed a high importance on seeking support from professionals with a specific interest in sport or who regularly worked with athletes, with the expectation that they would recognise the relative importance of sport for the athlete, as well as enabling athletes to relate to and engage with the clinician. Their main concerns seemed to be around the possibility of the athlete being stopped from training by a clinician who did not recognise the relative importance of sport to the athlete. Several of the coaches noted significant difficulties 
in sourcing such athlete-specific support, both for eating psychopathology and for more general mental health issues. A 54 year old club-based endurance coach noted:

In terms of physical problems then we know local physios we've got contact with those, we've got a good support network for things like that. But when it's a mental health issue, there really isn’t anything I know of that I can go to and get any help.

Club based coaches working with sub-elite level athletes described finding and accessing athlete-specific support as a particular problem. A wide variety of support options was perceived to exist for elite level athletes, but this was not the case for athletes not quite at this level. Indeed, coaches noted the considerable financial difficulties for sub-elite athletes in seeking psychological, medical or nutritional support. One 56 year old university endurance coach suggested that coaches working with all levels of athletes should be able to seek specific support through the governing body: “Any old coach should be able to say I've got a problem and somebody should be able to pick it up. Now that can't be done right now.”

Persuading athletes to seek treatment. Persuading an athlete to acknowledge they had an eating problem was described as particularly difficult by coaches, especially for adult athletes, where parental involvement was minimal and coaches were unable to call upon them for their support. In addition, coaches identified considerable reluctance among their athletes to seek help for eating problems, even when they acknowledged it was an issue. Whilst many of the coaches felt able to explain the risks and the importance of seeking support for an eating problem, motivating the athlete to seek help was identified as the most difficult challenge, as one 69-year old club-based endurance coach described:

But that is the hardest part, that is by far the hardest part, as I said, this particular girl I coached, she accepted everything, she understood exactly what I was saying and why and the reasoning behind it, but could not get herself to do it. 


\section{Discussion}

This study explored how track and field coaches respond to athletes with eating problems, and investigated the challenges they encounter when doing so. Three themes emerged of strategies that coaches employ when working with an athlete with an eating problem; Supportive, Avoidant and Confrontational. A fourth theme identified the challenges they faced, such as persuading affected athletes to seek treatment, and a lack of accessibility to support. The findings clearly distinguished between coaches who felt able to manage an athlete with an eating problem, and those who did not. Indeed, some coaches perceived dealing with athletes with eating problems to fall outside of the remit of their role as a coach. A tendency towards supportive strategies was evident where coaches had access to support networks and specialists, and where they felt able to tackle the eating problem in partnership with the athlete.

In contrast, avoidant strategies were characterised by passivity towards dealing with potential eating problems. Parents and medical staff were often relied upon to enforce training cessation or treatment seeking. Medical intervention and support is undoubtedly essential, particularly as the severity of an eating problem escalates; however, where coaches employ avoidant strategies, it is suggested they are failing to capitalise on their advantageous position to identify the early signs of disordered eating and potentially prevent the escalation to a clinical eating disorder (Selby \& Reel, 2011). The results indicated that a lack of confidence, poor knowledge about eating problems and a lack of available support can prevent coaches from taking decisive action.

Some coaches engaged closely with the treatment seeking process, while others were unwilling to acknowledge it as part of their role. The study explored experiences of voluntary track and field coaches, so these differences are perhaps unsurprising. The findings do 
however, raise questions as to what can be expected of coaches who work in a sport where eating disorders are prevalent (Sundgot-Borgen \& Torstveit, 2010), both in terms of identification and signposting. The findings reveal a coaching culture within which the psychological and emotional wellbeing of athletes is relatively neglected, which may contribute to the stigma that athletes perceive in disclosing mental health issues (Gulliver et al., 2012).

In contrast, some coaches who were willing to address potential eating problems adopted a confrontational approach that was characterised by an authoritarian style of coaching (Denison, 2007), where strict weight targets and rules were imposed. Such targets were often not sanctioned by medical professionals, but rather were identified by coaches themselves as appropriate. It is important to reinforce to coaches the need to seek medical support when assessing the weight status of athletes, particularly when this is the primary method used to determine if athletes can continue training. Coach beliefs about weight can easily transfer to athletes, reinforcing perceptions about the importance of weight for performance (Engel et al., 2003). In addition, weight monitoring and targets can exacerbate disordered eating among athletes and encourage perceptions of an 'ideal' body shape for their sport (Jones et al., 2005; McMahon \& Dinan-Thompson, 2008). There is a clear need for comprehensive coach education on disordered eating in sport. Improving knowledge and literacy about eating problems will help to empower coaches to take a more active role in managing and responding to potential eating problems among their athletes.

Supportive strategies were concomitant with a greater coach involvement in the treatment seeking process. Coaches can provide valuable insight into changes in training behaviours, competitive performances, and eating attitudes among athletes with eating problems (Plateau et al., 2013); and they are also likely to be instrumental in facilitating the athlete's transition back into competitive sport after treatment (Thompson \& Sherman, 2010). 
Encouraging coaches to remain actively involved during the treatment process, is likely to facilitate communication between the coach and the clinician with regards to the resumption of the athlete’s training (Thompson \& Sherman, 2010).

The three response styles that emerged in this study fit well with literature exploring parenting styles (Baumrind, 1967) and responses of carers of people with eating disorders (Treasure et al., 2007). Supportive coach responses can be likened to the Dolphin carer or the Authoritative parent, while an avoidant coach response can be likened to the Permissive parent, and the Ostrich carer. Similarly, confrontational strategic approaches can be likened to the Authoritarian parenting style, and the Rhinoceros carer (Baumrind, 1967, Treasure et al., 2007). Resources for carers have incorporated animal metaphors to facilitate recognition of their own response styles and to promote alternative ways to deal with eating disorders (Treasure et al., 2007). It is suggested that the themes reported in this study are not mutually exclusive, with various factors influencing the strategic approach taken by each coach. Indeed, it is important to note that some of the coaches in this study demonstrated elements of the three themes, suggesting a rather confused approach to managing the eating problem, and lacking a clear strategy. In addition to coach knowledge and experience of disordered eating, factors such as the quality of the coach-athlete relationship, the athlete's age and the availability of support services, are some additional factors that are likely to influence coach responses. It may be useful to incorporate the findings from this study into eating disorders education for coaches, to facilitate recognition of response styles, potential influencing factors, and the strengths and limitations of each strategy.

The coaches experienced difficulties in persuading athletes to seek help for an eating problem; an issue that has also been identified by elite level coaches (Nowicka et al., 2013). Athletes are often reluctant to seek mental health support due to concerns over the associated stigma (Gulliver et al., 2012). In addition, clinical studies have indicated that patients can 
perceive the benefits of retaining an eating disorder to outweigh those of recovery (e.g., Nordbo et al., 2012). Exploring the potential benefits that athletes attribute to retaining an eating problem is therefore an important line of enquiry, specifically to inform the development of athlete-specific interventions.

This study has important implications as to how UK track and field coaches can be better assisted in supporting athletes with eating problems. It highlights the importance of providing resources, local contacts and governing body endorsed protocols to improve coach confidence and empower them to address eating problems at an early stage. Importantly, early intervention for eating disorders is associated with a more positive treatment outcome (Reas, Williamson, Martin \& Zucker, 2000; Zipfel, Lowe, Reas, Deter \& Herzog, 2000). It is necessary to reinforce with coaches the key role that they play in identifying eating problems and facilitating help seeking among their athletes (Plateau et al., 2013; Selby \& Reel, 2011).

This study included a small sample of track and field, highly experienced, older male coaches. The majority of qualified, volunteer coaches are male (Sports Coach UK, 2011), hence the sample closely reflects the UK coaching demographic. The findings are consistent with results from elite coaches (Nowicka et al., 2013), suggesting that difficulties experienced in accessing support and persuading athletes to seek treatment are pervasive regardless of sport or level of coaching. This exploratory study can inform the development of a quantitative measure of coach responses when faced with athletes with eating problems. It is plausible to suggest that the strategic approaches identified in this study may differentiate coach responses in other challenging situations, beyond eating problems. Future research exploring and mapping the relative success of coach strategies through assessing helpseeking behaviour among athletes will further validate the strategies identified in this study.

\section{Perspectives}


Athletes are at an increased risk of eating problems, and coaches are in an advantageous position to identify and intervene. This study is innovative in exploring eating problems in track and field athletes from the perspective of the volunteer coach. The findings have important implications for coach education, most notably the need to empower coaches in their early intervention role, through improving coach knowledge of eating problems in sport, and urging coaches to take an active role in supporting athletes with eating problems. Coaches should be encouraged to work in collaboration with the clinical team, to determine when training and competition can be reintroduced. Finally, coaches can be encouraged to identify their own responses to athletes with eating problems, and to acknowledge the advantages and limitations of such strategies.

\section{References}

Arthur-Cameselle JN, Baltzell A. Learning from collegiate athletes who have recovered from eating disorders: Advice to coaches, parents and other athletes with eating disorders. J Appl Sport Psychol 2012: 24: 1-9.

Aquilino WS. Interview mode effects in surveys of drug and alcohol use: A field experiment. Public Opin Quart 1994: 58: 210-240

Barter C \& Renold E. 'I wanna tell you a story’: Exploring the application of vignettes in qualitative research with children and young people. Int J Soc Res Meth 2000: 3: 307323.

Baumrind D. Child care practices anteceding three patterns of preschool behavior. Genet Psychol Monogr 1967: 75: 43-88.

Bhaskar R. Reclaiming reality: A critical introduction to contemporary philosophy. London: Verso; 1989. 
Bennell KL, Malcolm SA, Thomas SA., Reid SJ, Brukner PD, Ebeling PR, Wark JD. Risk factors for stress fractures in track and field athletes. A twelve-month prospective study. Am J Sport Med 1996a: 24: 810-818.

Braun V, Clarke V. Using thematic analysis in psychology. Qual Res Psychol 2006: 3: 77101.

Denison J. Social theory for coaches: A foucauldian reading of one athlete’s poor performance. Int J Sport Sci Coaching 2007: 2: 369-383.

Duckham RL, Peirce N, Meyer C, Summers GD, Cameron N, Brooke-Wavell K. Risk factors for stress fracture in female endurance athletes: A cross sectional study. BMJ Open 2012: 2: e001920. doi:10.1136/bmjopen-2012-001920

Engel SG, Johnson C, Powers PS, Crosby RD, Wonderlich SA, Wittrock DA, Mitchell JE. Predictors of disordered eating in a sample of elite Division I college athletes. Eat Beh 2003: 4: 333-343.

Goodwin H, Arcelus J, Marshall S, Wicks S, Meyer, C. Critical comments concerning shape and weight: Associations with eating psychopathology among full-time dance students. Eat Weight Disord 2013: Doi: 10.1007/s40519-013-0075-2

Guest G, Bunce A, Johnson L. How many interviews are enough? An experiment with data saturation. Field Method 2006: 18: 59-82

Gulliver A, Griffiths KM, Christensen H. Barriers and facilitators to mental health helpseeking for young elite athletes: a qualitative study. BMC Psychiatry 2012: 12: 157.

Hunt J, Eisenberg D. Mental health problems and help-seeking behavior among college students. J Adolescent Health 2010: 46: 3-10. 
Hausenblas HA, McNally K. Eating disorder prevalence and symptoms for track and field athletes and nonathletes. J Appl Sport Psychol 2004: 16: 274-286.

Hughes R. Considering the vignette technique and its application to a study of drug injecting and HIV risk and safer behaviour. Sociol Health Ill 1998: 20: 381-400.

Johnson C, Powers PS, Dick R. Athletes and eating disorders: The National Collegiate Athletic Association study. Int J Eat Disorder 1999: 26: 179-188.

Jones RL, Glintmeyer N, McKenzie A. Slim bodies, eating disorders and the coach-athlete relationship: A tale of identity creation and disruption. Int Rev Sociol Sport 2005: 40: 377-391.

Jowett S, Cockerill IM. Olympic medallists’ perspectives of the athlete-coach relationship. Psychol Sport Ex 2003: 4: 313-331.

Kristiansen E, Tomten SE, Hanstad DV, Roberts C. Coaching communication issues with elite female athletes: Two Norwegian case studies. Scand J Med Sci Spor 2012: 22: e156-e157.

Lentillon-Kaestner V, Hagger MS, Hardcastle S. Health and doping in elite level cycling. Scand J Med Sci Spor 2012: 22: 596-606.

McMahon JA, Dinan-Thompson M. A malleable body - revelations from an Australian elite swimmer. Healthy Lifestyles Journal 2008: 54: 1-6.

McMahon JA, Penney D, Dinan-Thompson M. Body practices- exposure and effect of a sporting culture? Stories from three Australian swimmers. Sport Educ Soc 2012: 17: 2: 181-206. 
Muscat AC, Long BC. Critical comments about body shape and weight: Disordered eating of female athletes and sport participants. J Appl Sport Psychol 2008: 20: 1-24.

National Collegiate Athletic Association. NCAA coaches handbook: Managing the female athlete triad. Indianapolis, IN: 2005.

Nattiv A. Stress fractures and bone health in track and field athletes. J Sci Med Sport 2000: 3: 368-379.

Nordbo RHS, Espeset EMS, Gulliksen KS, Skarderud F, Geller J, Holte A. Reluctance to recover in anorexia nervosa. Eur Eat Disord Rev 2012: 20: 60-67.

Nowicka P, Eli K, Ng J, Apitzsch E, Sundgot-Borgen J. Moving from knowledge to action: A qualitative study of elite coaches' capacity for early intervention in cases of eating disorders. Int J Sports Sci Coach 2013: 8: 343-355.

NVivo qualitative data analysis software; QSR International Pty Ltd. Version 9, 2010

Partington M, Cushion C. An investigation of the practice activities and coaching behaviors of professional top-level youth soccer coaches. Scand J Med Sci Spor 2013: 23: 374382.

Patton, M.Q. Qualitative evaluation and research methods, $3^{\text {rd }}$ ed. London: Sage; 2002.

Petrie TA, Greenleaf C, Reel J, Carter J. Personality and psychological factors as predictors of disordered eating among female collegiate athletes. Eat Disord 2009: 17: 302-321.

Pilgrim D, Rogers A. Mental health, critical realism and lay knowledge. In Ussher JM (Ed). Body Talk. New York: Routledge; 2002. 
Plateau CR, McDermott HJ, Arcelus J, Meyer C. Identifying and preventing disordered eating among athletes: Perceptions of track and field coaches. Psychol Sport Exerc: 2013: 10.1016/j.psychsport.2013.11.004

Pollock N, Grogan C, Perry M, Pedlar C, Cooke K, Morrissey D, Dimitriou L. Bone-mineral density and other features of the female athlete triad in elite endurance runners: A longitudinal and cross-sectional observational study. Int J Sport Nutr Ex 2010: 20: 418-426.

Reas DL, Williamson DA, Martin CK, Zucker NL. Duration of illness predictos outcome for bulimia nervosa: A long term follow-up study. 428-466.

Schmidt U, Treasure J. Anorexia nervosa: Valued and visible. A cognitive-interpersonal maintenance model and its implications for research and practice. Brit J Clin Psychol 2006: 45: 343-366.

Selby C, Reel JJ. A coach’s guide to identifying and helping athletes with eating disorders. J Sport Psychol Action 2011: 2: 100-112.

Shanmugam, V, Jowett S, Meyer, C. Eating psychopathology amongst athletes: the importance of relationships with parents, coaches and teammates. Int J Sport Ex Psychol 2013: 11: 24-38.

Sherman RT, Thompson RA, Dehass D, Wilfert M. NCAA coaches survey: The role of the coach in identifying and managing athletes with disordered eating. Eat Disord 2005: 13: 447-466.

Smith JA (Ed.). Qualitative psychology: A practical guide to research methods; 2008. London: Sage. 
Smith B, \& Caddick N. Qualitative methods in sport: A concise overview for guiding social scientific sport research. Asia Pac J Sport Social Sci 2012: 1: 60-73

Sports Coach UK. Sports Coaching in the UK III: A statistical analysis of coaches and coaching in the UK; 2011. Available from: http://www.sportscoachuk.org

Sturges JE, Hanrahan KJ. Comparing telephone and face-to-face qualitative interviewing: a research note. Qual Res 2004: 4: 107-118.

Sundgot-Borgen J. Risk and trigger factors for the development of eating disorders in female elite athletes. Med Sci Sport Ex 1994: 26: 414-419.

Sundgot-Borgen J, Torstveit MK. Prevalence of eating disorders in elite athletes is higher than in the general population. Clin J Sport Med 2004: 14: 25-32.

Sundgot-Borgen J, Torstveit MK. Aspects of disordered eating continuum in elite highintensity sports. Scandi J Med Sci Sports 2010: 20 (S2): 112-121.

Thompson R, Sherman RT. Eating Disorders in Sport. Routledge; 2010.

Torstveit MK, Rosenvinge JH, Sundgot-Borgen J. Prevalence of eating disorders and the predictive power of risk models in female elite athletes: A controlled study. Scand J Med Sci Sport 2008: 18: 108-118.

Treasure J, Smith G, Crane A. Skills-based learning for caring for a loved one with an eating disorder: The new Maudsley method. London: Routledge; 2007.

Tong A, Sainsbury P, Craig J. Consolidated criteria for reporting qualitative research (COREQ): A 32-item checklist for interviews and focus groups. Int J Qual Health C 2007: 19: 349-357. 
Turk JC, Prentice WE, Chappell S, Shields EW. Collegiate coaches’ knowledge of eating disorders. J Athl Training 1999: 34: 19-24.

UK Athletics. Support and referral processes. Presented at UKA Eating Disorders Seminar. Loughborough, 2013.

UK Sport. Eating disorders in sport. A guideline framework for practitioners working with high performance athletes; 2007. Available from: http://www.uksport.gov.uk/

Whitaker L, Backhouse SH, Long J. Reporting doping in sport: National level athletes’ perceptions of their role in doping prevention. Scand J Med Sci Spor 2014: doi: 10.1111/sms.12222.

Zipfel S, Löwe B, Reas DL, Deter HC, Herzog W. Long term prognosis in anorexia nervosa: Lessons from a 21 year follow up study. Lancet 2000: 355: 721-2. 
Table 1

Participant Characteristics

$$
(n=11)
$$

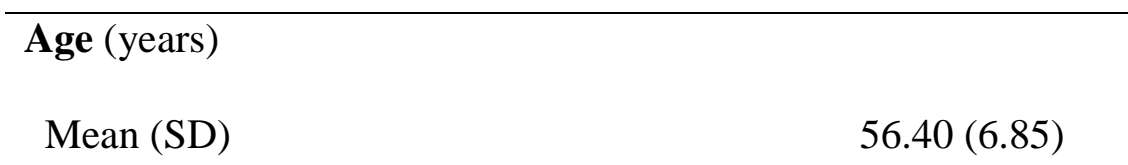

Sex

$\begin{array}{ll}\text { Female/male } & 1 / 10\end{array}$

Coaching qualification ${ }^{1}$

Level 2

Level $3 \quad 6$

Level $4 \quad 4$

Hours coaching per week

Mean (SD) $9.82(4.50)$

Years of coaching experience

Mean (SD) $\quad 23.60$ (12.01)

\section{Disciplines coached}

Middle-long distance $\quad 10$

Field events 1

Highest level of athletes currently coaching

National 5

International 6

\footnotetext{
${ }^{1}$ Level 2 coaches can coach independently across all running, jumping and throwing disciplines within athletics. Level 3 coaches have developed some specialisation such as specialising within running, jumping or throwing. Level 4 coaches have specialised yet further and are classified as specialist coaches for particular events, such as $800 \mathrm{~m}$ and $1500 \mathrm{~m}$.
} 
Table 2

Interview Schedule

\section{Questions and Prompts}

Demographics; coaching history. Weight monitoring strategies; education in disordered eating

Could you describe your experiences with an athlete with an eating problem?

Prompts: How did you know the athlete had problems with their eating? What did you do when you suspected an eating problem?

Did you approach or challenge the athlete about their eating problem?

Prompts: If yes, can you describe the interaction? Was it a success? If no, why? How did you feel about asking the athlete about their eating? Was the athlete willing to talk to you?

What action (if any) did you recommend to the athlete, or take yourself?

Prompts: Did the athlete readily accept or acknowledge their eating problem? Did you approach anyone else to for support? Did you know where to seek help from? With hindsight, was there anything that would have been useful to know about/have access to?

\section{Disordered eating scenario}

Part 1: Sarah is a talented 18 year old female at your club. She works extremely hard both at her university course and in athletics, and has recently expressed a desire to do additional training beyond her current schedule. She says she wants to succeed and will do whatever it takes. Her performances on the track have been good and she has a chance of being selected to compete for the GB Junior team this year. You notice that Sarah has lost weight in the last few weeks and that she has become more rigid about her diet, excluding most carbohydrates.

Part 2: Three months later and Sarah's performance has dropped considerably. Her weight has continued to fall and she complains of feeling tired a lot. She admits to you that she has not been eating properly and sometimes makes herself sick after mealtimes.

After each part of the scenario, coaches were asked: How comfortable would you feel in tackling these issues? What would you say to the athlete and what advice would you give? 